\title{
Derivatives of aryl amines containing the cytotoxic 1,4-dioxo-2-butenyl pharmacophore
}

\author{
Amitabh Jha ${ }^{\mathrm{a}, *}$, Chandrani Mukherjee ${ }^{\mathrm{a}, \mathrm{b}}$, Ashok K. Prasad ${ }^{\mathrm{b}}$, Virinder S. Parmar ${ }^{\mathrm{b}}$, Manjula Vadaparti ${ }^{\mathrm{a}}$, \\ Umashankar Das ${ }^{c}$, Erik De Clercq ${ }^{\mathrm{d}}$, Jan Balzarini ${ }^{\mathrm{d}}$, James P. Stables ${ }^{\mathrm{e}}$, Anuraag Shrivastav ${ }^{\mathrm{f}}$, \\ Rajendra K. Sharma ${ }^{f}$, Jonathan R. Dimmock ${ }^{c}$ \\ a Department of Chemistry, Acadia University, Wolfville, NS, Canada B4P 2R6 \\ ${ }^{\mathrm{b}}$ Department of Chemistry, University of Delhi, Delhi 110 007, India \\ ${ }^{\mathrm{c}}$ College of Pharmacy and Nutrition, University of Saskatchewan, Saskatoon, SK, Canada S7N 5C9 \\ ${ }^{\mathrm{d}}$ Rega Institute for Medical Research, Katholieke Universiteit Leuven, B-3000 Leuven, Belgium \\ ${ }^{\mathrm{e}}$ National Institute of Neurological Disorders and Stroke, NIH, Bethesda, MD 20852, USA \\ ${ }^{\mathrm{f}}$ Department of Pathology, College of Medicine, University of Saskatchewan, and Cancer Research Unit, Saskatoon, SK, Canada S7N 4H4
}

\section{A R T I C L E I N F O}

\section{Article history:}

Received 5 December 2009

Accepted 19 January 2010

Available online 25 January 2010

\section{Keywords:}

1,4-Dioxo-2-butenyl

Cytotoxicity

$N$-Arylmaleamates

$\mathrm{N}$-Arylfumaramates

$\mathrm{N}$-Arylmaleimides

$\mathrm{N}$-Arylisomaleimides

Structure-activity relationships

Molecular modeling

\begin{abstract}
A B S T R A C T
Several series of compounds containing the 1,4-dioxo-2-butenyl moiety have been prepared as candidate cytotoxins, including the methyl $\mathrm{N}$-arylmaleamates, methyl $\mathrm{N}$-arylfumaramates, and $\mathrm{N}$-arylmaleimides. In addition, the $\mathrm{N}$-arylisomaleimides were synthesized which are the structural isomers of $\mathrm{N}$-arylmaleimides. These compounds were evaluated against human Molt 4/C8 and CEM T-lymphocytes as well as murine L1210 cells. Methyl $N$-arylfumaramates showed the highest cytotoxic potencies and, in particular, methyl $N$-(3,4-dichlorophenyl)fumaramate is six times more potent than melphalan towards L1210 cells and is equipotent with this drug in the Molt 4/C8 assay. Electrophilicity of compounds under investigation was demonstrated by carrying out thiolation using model benzyl mercaptan on representative compounds. Methyl $\mathrm{N}$-(3,4-dichlorophenyl)fumaramate and methyl $\mathrm{N}$-(4-chlorophenyl)maleamate inhibited human $N$-myristoyltransferase, a possible molecular target, in high micromolar range. QSAR and molecular modeling revealed some correlations between different structural features of a number of the molecules and cytotoxic potencies. Methyl $\mathrm{N}$-arylfumaramates were well tolerated in mice in comparison to the analogs in other series of compounds tested. The data obtained in this investigation affords guidelines for preparing new series of molecules with greater potencies.
\end{abstract}

(c) 2010 Elsevier Ltd. All rights reserved.
A major interest of these laboratories is the design, syntheses, and bioevaluations of $\alpha, \beta$-unsaturated ketones. ${ }^{1-7}$ These compounds have an affinity for thiols but are either unreactive or less reactive towards amino and hydroxy groups. ${ }^{8,9}$ Since these latter two functionalities are present in nucleic acids, administration of conjugated enones may not cause the genotoxic effects which are displayed in a number of contemporary anticancer drugs. ${ }^{10}$ Thiols react at the $\beta$ carbon atom of conjugated enones. Hence the placement of an additional carbonyl group on the $\beta$ carbon atom should deplete the electron density on the olefinic carbon atoms and increase the rates of thiol alkylation in the cell compared to the enone moiety. One of the objectives of the present investigation was to ascertain whether the 1,4-dioxo-2-butenyl group is a cytotoxic pharmacophore when incorporated into a variety of ligands.

Several years ago, the $N$-arylmaleamic acids 1 (Fig. 1 ) were prepared and this series was chosen as the starting point in this inves-

\footnotetext{
* Corresponding author. Tel.: +1 902585 1515; fax: +1 9025851114

E-mail address: ajha@acadiau.ca (A. Jha).
}

tigation since it has not only the 1,4-dioxo-2-butenyl group (hereafter referred to as the enedione moiety) but also an aryl ring into which can be placed different substituents to modulate potency. These compounds were evaluated against human Molt 4/C8 and CEM T-lymphocytes as well as murine L1210 cells and were either weakly active $\left(\mathrm{IC}_{50}\right.$ values of $\left.43-290 \mu \mathrm{M}\right)$ or had $\mathrm{IC}_{50}$ figures in excess of $500 \mu \mathrm{M} .{ }^{11}$ They were well tolerated in mice whereby doses up to and including $300 \mathrm{mg} / \mathrm{kg}$ did not cause any mortalities.

The reasons for the design of analogs of series $\mathbf{1}$ are as follows. The low potencies of $\mathbf{1 a - i}$ may have been due to the polar carboxy group which impedes passage via the cell membrane of cancer cells. Hence the formation of the corresponding esters $\mathbf{2}$ was suggested. The hypothesis was formulated that the cytotoxic potencies of the compounds related to the $\mathrm{N}$-arylmaleamic acids is controlled principally by the olefinic and aryl groups and also the topographical relationship between these two structural moieties. Such considerations led to the proposal to synthesize series 3-6. The olefinic double bond in series $\mathbf{1}$ and $\mathbf{2}$ adopts the $Z$ configura- 


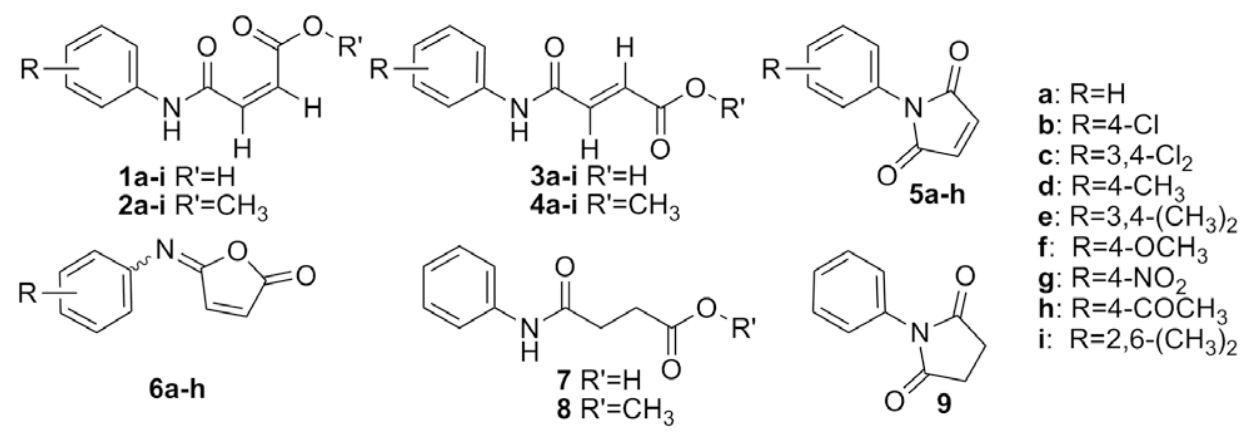

Figure 1. Molecular structures of compounds studied.

tion and a comparison with the potencies of the $E$-isomers $\mathbf{3}$ and $\mathbf{4}$ was planned. In order to examine the effect of compressing the enedione group into a ring, series $\mathbf{5}$ was suggested. The decision was made to prepare the $N$-arylmaleisoimides $\mathbf{6}$ in which the olefinic group is adjacent to both carbonyl and imino moieties. As a null hypothesis, the reduction of the olefinic double bond of $\mathbf{1 a}$ (or 3a), 2a (or 4a), and 5a leading to 7-9 (Fig. 1) was considered in order to confirm that the olefinic group is important in conferring cytotoxic properties. Confirmation of the thiol-alkylating properties of these compounds was proposed, whereby representative compounds in each of the series 1-6 would react with a model thiol, namely benzyl mercaptan. In addition, such experiment with benzyl mercaptan would indicate at which olefinic carbon atoms thiolation takes place.

The choice of aryl substituents in series 1-6 was made on the basis of their differing electronic, hydrophobic and steric properties. Thus groups with positive (+) or negative (-) Hammett $\sigma$ (a descriptor of electronic substituent effect on aromatic rings) and Hansch $\pi$ (a descriptor of hydrophobic/hydrophilic character) values were utilized viz $+\sigma /+\pi(\mathbf{b}, \mathbf{c}),-\sigma /+\pi(\mathbf{d} / \mathbf{e}),+\sigma /-\pi(\mathbf{g , h})$, and $-\sigma /-\pi$ (f) while the molar refractivity (MR; a descriptor of steric bulk) figures of the substituents b-i ranged from 5.65 (d) to $11.18(\mathbf{h})$.

In summary, the objectives of the present study were as follows. First, an evaluation would be made to determine whether the enedione group is a cytotoxic pharmacophore which could be used as a building block in developing more complex ligands. In this regard, the recent recommendations of starting projects with lead molecules having low molecular weights of 300-400 and moderate potencies in the micromolar range is of relevance. ${ }^{12}$ Second, an estimate would be made of the influence of the location of this putative pharmacophore in different series of compounds in regard to cytotoxic potencies. Third, the spatial relationship between the aryl ring and the enedione group may influence the $\mathrm{IC}_{50}$ values. Fourth, the possibility exists that the nature of the aryl substituents exerts a statistically significant effect on the magnitude of the biological responses. The comparisons of the potencies of the compounds was planned to be achieved using the Molt 4/C8, CEM, and L1210 screens.

The synthetic chemical routes followed in producing the compounds in series 1-9 are outlined in Scheme 1. The reaction of an aryl amine with maleic anhydride led to the synthesis of the $\mathrm{N}$-arylmaleamic acids $\mathbf{1}$ which were converted into the corresponding methyl esters $\mathbf{2}$. While $\mathbf{2 f}$ was formed, it was very unstable reverting to $\mathbf{1 f}$ and hence it was not evaluated for bioactivity. The dehydration of $\mathbf{1 a}-\mathbf{h}$ led to $\mathbf{5 a}-\mathbf{h}$ under thermodynamically controlled conditions and $\mathbf{6 a}-\mathbf{h}$ when the reaction was controlled kinetically. ${ }^{13,14}$ Reaction of various aryl amines with fumaryl chloride led to the isolation of the corresponding $\mathrm{N}$-arylfumaramic acids 3a-i which were esterified with methanol leading to $\mathbf{4 a}-\mathbf{i}$. Condensation of aniline with succinic anhydride produced the corresponding acid $\mathbf{7}$ from which the ester $\mathbf{8}$ and dehydrated product $\mathbf{9}$ were obtained.

All compounds of series 2-6 and compounds 6-9 were evaluated against human Molt 4/C8, and CEM T-lymphocytes as well as murine leukemic L1210 cells. The results are given in Table 1. Representative compounds, namely $\mathbf{2 c}, \mathbf{d}, \mathbf{4 b}, \mathbf{c}, \mathbf{e}$ and $\mathbf{3 b}-\mathbf{e , g}$ were evaluated as inhibitors of human $N$-myristoyltransferase (hNMT). Murine toxicity of $\mathbf{2 b}-\mathbf{d}, \mathbf{g}, \mathbf{h}, \mathbf{3 a}-\mathbf{i}, \mathbf{4 a}-\mathbf{c}, \mathbf{e}-\mathbf{g}, \mathbf{i}, \mathbf{5 a}-\mathbf{h}, \mathbf{6 b}, \mathbf{c}, \mathbf{g}, \mathbf{h}$, and 8 was assessed by injecting doses of 30,100 , and $300 \mathrm{mg} / \mathrm{kg}$ into mice and the animals were examined at the end of $0.5-4 \mathrm{~h}$ for mortalities.

The cytotoxic evaluation of $\mathbf{2} \mathbf{a}-\mathbf{e}, \mathbf{g}-\mathbf{i}, \mathbf{3 a}-\mathbf{i}, \mathbf{4 a}-\mathbf{h}, \mathbf{5 a}-\mathbf{h}$, and $\mathbf{6}-\mathbf{8}$, 9a-i was undertaken using Molt 4/C8 and CEM T-lymphocytes in order to assess whether the compounds demonstrate antineoplastic properties towards human transformed cells. The murine L1210 bioassay was used as a number of anticancer drugs inhibit the growth of this cell line ${ }^{15}$ and hence this screen may reveal lead compounds. The reference anticancer drug used in this study was the alkylating agent melphalan. Of particular note is the observation that $\mathbf{3 c}$ is six times more potent than melphalan towards L1210 cells and equipotency with melphalan was achieved by 3c,e in the Molt 4/C8 assay and by $3 \mathbf{e}$ in the L1210 test.

Correlations between the structures of the compounds in series 2-5 and cytotoxic potencies were sought in order to provide guidelines for expansion of this study. Three approaches were employed in the analysis of the biodata. First, qualitative and quantitative comparisons of the $\mathrm{IC}_{50}$ values between different series of compounds were undertaken. Second, the importance of various physicochemical constants of the aryl substituents in determining cytotoxic potencies was assessed. Third, molecular modeling was used to determine if the relative positions of certain functional groups influenced the potencies of the compounds.

Comparisons of the relative cytotoxic potencies between clusters of molecules enabled the following conclusions to be drawn. (1) The biodata presented in Table 1 reveal that the esters and amides which contain the enedione moiety, namely series $\mathbf{2 - 4}$, inhibit the growth of all three cell lines with the exception of $\mathbf{2 a}$. Hence the hypothesis that the enedione is a cytotoxic pharmacophore appears to be valid. The conclusion was strengthened by the fact that when the olefinic double bond in $\mathbf{2 a}$, 3a and $\mathbf{4 a}$ was reduced, leading to $\mathbf{7}$ and $\mathbf{8}$, cytotoxic properties were abolished. (2) The conversion of the $\mathrm{N}$-arylmaleamic and $\mathrm{N}$-fumaramic acids to the corresponding methyl esters led to increases in cytotoxicity in most cases. Thus a comparison between the literature $\mathrm{IC}_{50}$ values of series $\mathbf{1}^{11}$ with corresponding methyl esters $\mathbf{2}$ revealed greater cytotoxic potencies in series $\mathbf{2}$. Similarly all of the compounds in series $\mathbf{4}$ had greater cytotoxic potencies than the precursor $\mathrm{N}$-arylfumaramic acids 3. (3) In order to compare the potencies of the compounds in series $\mathbf{2 - 4}$, the following procedures were adopted. The $\mathrm{IC}_{50}$ values of the compounds containing the same aryl substituent were compared and a score of 3 (greatest potency), 


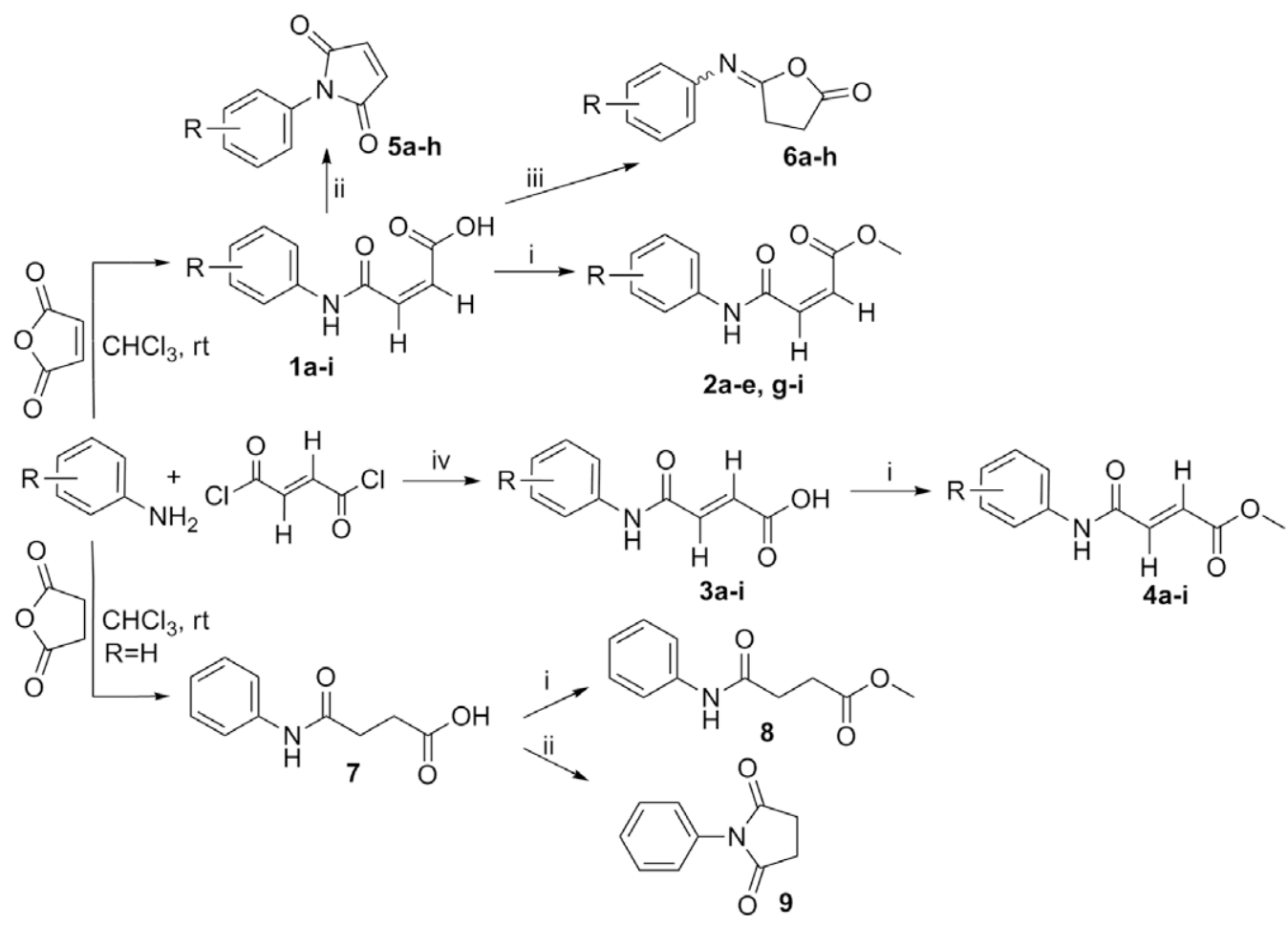

Scheme 1. Reagents and conditions: (i) $\mathrm{CH}_{3} \mathrm{OH} / \mathrm{H}^{+}$; (ii) $\left(\mathrm{CH}_{3} \mathrm{CO}\right)_{2} \mathrm{O}, \mathrm{CH}_{3} \mathrm{COO}^{-} \mathrm{Na}^{+}$; (iii) $\left(\mathrm{CF}_{3} \mathrm{CO}\right)_{2} /$ dioxane; (iv) (a) $\mathrm{NaOH}$; (b) $\mathrm{HCl}$.

Table 1

Evaluation of 2a-e,g-i, 3a-i, 4a-i, 5a-h, 6a-h, and 7-9 against Molt 4/C8, CEM and L1210 cells

\begin{tabular}{lllc}
\hline Compound $^{\mathrm{a}, \mathrm{b}}$ & \multicolumn{3}{c}{$\mathrm{IC}_{50}(\mu \mathrm{M})$} \\
\cline { 2 - 4 } & Molt 4/C8 & CEM & $\mathrm{L} 1210$ \\
\hline $\mathbf{2 b}$ & $41 \pm 1$ & $95 \pm 62$ & $78 \pm 3$ \\
$\mathbf{2 c}$ & $41 \pm 7$ & $55 \pm 25$ & $39 \pm 6$ \\
$\mathbf{2 d}$ & $37 \pm 5$ & $36 \pm 4$ & $47 \pm 15$ \\
$\mathbf{2 h}$ & $50 \pm 9$ & $44 \pm 3$ & $184 \pm 22$ \\
$\mathbf{4 a}$ & $42 \pm 0$ & $40 \pm 1$ & $40 \pm 4$ \\
$\mathbf{4 b}$ & $8.2 \pm 0.1$ & $9.6 \pm 0.1$ & $7.5 \pm 2.4$ \\
$\mathbf{4 c}$ & $2.4 \pm 0.3$ & $4.8 \pm 0.1$ & $0.37 \pm 0.29$ \\
$\mathbf{4 d}$ & $21 \pm 4$ & $15 \pm 1$ & $9.3 \pm 0.4$ \\
$\mathbf{4 e}$ & $4.6 \pm 2.3$ & $7.6 \pm 0.00$ & $2.2 \pm 0.3$ \\
$\mathbf{4 f}$ & $10 \pm 0$ & $37 \pm 3$ & $18 \pm 10$ \\
$\mathbf{4 g}$ & $7.3 \pm 0.7$ & $11 \pm 1$ & $6.2 \pm 0.8$ \\
$\mathbf{4 h}$ & $35 \pm 2$ & $32 \pm 2$ & $17 \pm 5$ \\
$\mathbf{4 i}$ & $26 \pm 2$ & $31 \pm 5$ & $34 \pm 7$ \\
$\mathbf{5 c}$ & $43 \pm 1$ & $44 \pm 4$ & $37 \pm 9$ \\
$\mathbf{5 d}$ & $43 \pm 1$ & $42 \pm 1$ & $7.8 \pm 0.4$ \\
$\mathbf{5 e}$ & $29 \pm 3$ & $35 \pm 7$ & $8.1 \pm 0.1$ \\
Melphalan & $3.2 \pm 0.8$ & $2.5 \pm 0.0$ & $2.1 \pm 0$ \\
\hline
\end{tabular}

${ }^{\text {a }}$ Compounds $\mathbf{2 a}, \mathbf{e}, \mathbf{g}, \mathbf{i}, \mathbf{3 a}-\mathbf{i}, \mathbf{5 a}, \mathbf{b}, \mathbf{f}, \mathbf{6 a}, \mathbf{d}, \mathbf{f}, \mathbf{h}, \mathbf{7}, \mathbf{8}$, and $\mathbf{9}$ were inactive against the three cell lines tested $\left(\mathrm{IC}_{50}>150 \mu \mathrm{M}\right)$.

b Compounds $\mathbf{5 g , h}, \mathbf{6 b}, \mathbf{c}, \mathbf{e}, \mathbf{g}$ were moderately active with $\mathrm{IC}_{50}$ values in the range $50-250 \mu \mathrm{M}$ against the three cell lines tested with at least one value $<100 \mu \mathrm{M}$ (see Supplementary data).

2 and 1 (lowest potency) were made. Standard deviations were taken into account and six points were invariably awarded, for example, if two compounds had greater potencies than a third molecule, then the scoring would be $2 \frac{1}{2}, 21 / 2$ and 1 , respectively. A comparison of the $\mathrm{IC}_{50}$ values of $\mathbf{2 a - e , g , h}, \mathbf{3 a - e , g , h}$, and $\mathbf{4 a - e , g , h}$ were made and the results are summarized in Table 2 . The results indicate that in terms of the potency scores, the $\mathrm{N}$-arylfumaramate esters 3 , having the $E$ conformation of the olefinic double bond, are the most potent series of compounds. The $\mathrm{N}$-arylmaleamates 2 and the $N$-arylmaleimides $\mathbf{4}$ in which the olefinic group adopts the $Z$ conformation have substantially lower potency scores. In addition, the average $\mathrm{IC}_{50}$ values of $\mathbf{3 a}-\mathbf{e}, \mathbf{g}, \mathbf{h}$ are lower than the analogs in series 2 and 4 . The perceptible lower $\mathrm{IC}_{50}$ figures of the compounds in series $\mathbf{4}$ than $\mathbf{2}$ suggests that the shape of $\mathbf{4}$ is preferred, such as its reduced flexibility and the relative positions of various atoms and groups being in different locations (vide infra). (4) In general, the maleimides $\mathbf{4 a - h}$ have greater cytotoxic potencies towards Molt 4/C8, CEM and L1210 cells than the isomaleimides 5. Thus when comparisons were made between compounds possessing the same aryl substituents, greater potency was displayed by series 4 and $\mathbf{5}$ in 63\% and 12\% of the cases, respectively, while equipotency was observed in $25 \%$ of the comparisons made. One may note that in both series $\mathbf{4}$ and $\mathbf{5}$ the murine L1210 cells are more sensitive to these compounds than the Molt 4/C8 and CEM T-lymphocytes. Also, 3,4-dichloro substitution (c) led to the most potent compounds in each of the series 2-5 in general.

Second, an investigation was conducted in order to gain insight into the contributions that the aryl substituents in series $\mathbf{2 b}-\mathbf{e}, \mathbf{g}-\mathbf{i}$, $\mathbf{4 a}-\mathbf{i}$, and $\mathbf{5 a}-\mathbf{h}$ made to cytotoxic potencies. Accordingly linear (lin) and semilogarithmic ( $\mathrm{sl}$ ) plots were made between the $\mathrm{IC}_{50}$ values obtained for each series of compounds with the Hammett $\sigma$ and Taft $\sigma^{*}$ values, then the Hansch $\pi$ figures and finally the molecular refractivity (MR) constants in the three bioassays. In addition, since all the MR values (but not the $\sigma$ or $\pi$ figures) are positive, logarith$\mathrm{mic} /$ semilogarithmic (lsl) and logarithmic (l) plots were constructed between the $\mathrm{IC}_{50}$ values in series $\mathbf{2}, \mathbf{4}$, and $\mathbf{5}$ and the MR constants. A negative correlation was noted between the $\mathrm{IC}_{50}$ figures of $\mathbf{5 a}-\mathbf{h}$ in the CEM screen and the $\pi$ values (lin, sl plots, $p<0.05$ ). In addition, a trend towards significance (sl plots, $p<0.1$ ) was observed between the $\mathrm{IC}_{50}$ data of $\mathbf{4 a - i}$ in the CEM test and $\mathbf{5 a} \mathbf{a}-\mathbf{h}$ in the Molt $4 / \mathrm{C} 8$ bioassay with the $\pi$ constants. These observations indicate that in the future the placement of highly lipophilic substituents in the aryl ring of the compounds in series $\mathbf{4}$ and $\mathbf{5}$ may lead to analogs with increased potencies. No other correlations $(p<0.05)$ nor trends to significance $(p<0.1)$ were observed.

Third, molecular modeling with representative molecules was undertaken in order to find if the relative locations of portions of 
Table 2

Comparison of the relative potencies of $\mathbf{2 a - e , g , h , ~} \mathbf{4 a - e , g , h}$, and $\mathbf{5 a} \mathbf{a}-\mathbf{e}, \mathbf{g}, \mathbf{h}$ towards Molt 4/C8, CEM and L1210 cells

\begin{tabular}{|c|c|c|c|c|c|c|c|c|}
\hline \multirow[t]{2}{*}{ Compounds } & \multicolumn{2}{|c|}{ Molt 4/C8 } & \multicolumn{2}{|c|}{ CEM } & \multicolumn{2}{|c|}{ L1210 } & \multicolumn{2}{|c|}{ OVERALL } \\
\hline & Potency score $^{\mathrm{a}}$ & Average $\mathrm{IC}_{50}(\mu \mathrm{M})$ & Potency score $^{\mathrm{a}}$ & Average $\mathrm{IC}_{50}(\mu \mathrm{M})$ & Potency score $^{\mathrm{a}}$ & Average $\mathrm{IC}_{50}(\mu \mathrm{M})$ & Potency score & Average $\mathrm{IC}_{50}(\mu \mathrm{M})$ \\
\hline $2 a-e, g, h$ & 10.5 & $>152$ & 11 & $>164$ & 8.5 & $>180$ & 30 & $>165$ \\
\hline $4 a-e, g, h$ & 20 & 17.2 & 21 & 17.1 & 19.5 & 11.8 & 60.5 & 15.4 \\
\hline $5 a-e, g, h$ & 11.5 & 120 & 10 & 141 & 14 & 70.0 & 35.5 & 110 \\
\hline
\end{tabular}

a The calculation of the potency scores is explained in the text.

the enediones 2, 4, and $\mathbf{5}$ influence cytotoxic potencies. Models were built of $\mathbf{2 a}, \mathbf{4 a}$, and $\mathbf{5 a}$ since they differ in potencies, that is, Table 1 revealed that $\mathbf{4 a}>\mathbf{5 a}>\mathbf{2 a}$ which reflects the relative potencies in general of series $\mathbf{2}, \mathbf{4}$, and $\mathbf{5}$ as indicated in Table 2 . The relative locations of the $\mathrm{C}^{1}, \mathrm{C}^{2}, \mathrm{O}^{1}$, and $\mathrm{O}^{2}$ atoms of the enedione moiety of $\mathbf{2 a}, \mathbf{4 a}$, and $5 \mathbf{a}$ are likely important determinants of cytotoxic potencies. These positions are referenced to the aryl ring which could also contribute to bioactivity by van der Waals bonding at a complementary binding site. An axis was constructed through carbon atoms 2 and 5 of the aryl ring as indicated in Figure 2 and the relative positions of the $C^{1}, C^{2}, O^{1}$, and $O^{2}$ atoms determined from the $d_{1}-d_{4}$ and $\psi_{1}-\psi_{4}$ measurements. These data are presented in Table 3.

The following observations were made. (1) The locations of the $\mathrm{O}^{1}$ and $\mathrm{C}^{1}$ atoms in $\mathbf{2 a}, \mathbf{4 a}$, and $\mathbf{5 a}$ are similar in relation to the aryl ring. Thus the $\Delta \%$ figures for $\mathrm{d}_{1}, \mathrm{~d}_{2}, \psi_{1}$, and $\psi_{2}$ determinations are less than $8 \%$. On the other hand the $\mathrm{d}_{3}, \mathrm{~d}_{4}, \psi_{3}$, and $\psi_{4}$ measurements varied considerably. Thus the reason for the potency differences between the compounds in series $\mathbf{2}, \mathbf{4}$, and $\mathbf{5}$ is controlled to a large extent by the relative positions of the $\mathrm{C}^{2}$ and $\mathrm{O}^{2}$ atoms. (2) The $d_{3}$ and $d_{4}$ spans are considerably higher in the most potent compound $4 \mathbf{a}$ than either $\mathbf{2 a}$ or $\mathbf{5 a}$. In addition, the lower $\psi_{3}$ and $\psi_{4}$ values of $\mathbf{4 a}$ indicate a different positioning of the terminal group $\left(=\mathrm{C}-\mathrm{C}(\mathrm{O}) \mathrm{OCH}_{3}\right)$. (3) The higher potency of $\mathbf{5 a}$ than $\mathbf{2 a}$ is likely associated with differences in the locations of the $\mathrm{C}^{2}$ and $\mathrm{O}^{2}$ atoms is evidenced by shorter $\mathrm{d}_{3}$ and $\mathrm{d}_{4}$ spans and larger $\psi_{3}$ and $\psi_{4}$ angles. Amplification of this project should bear in mind these results. For example, rigid analogs should ensure that the $\mathrm{d}_{3}$ and $\mathrm{d}_{4}$ distances are similar or larger than the figures for $\mathbf{4 a}$ and that the $\psi_{3}$ and $\psi_{4}$ angles do not exceed $50^{\circ}$.

The compounds under investigation (series 1-6), all being Michael acceptors, were expected to cause protein thiolation. A number of studies report that protein thiolation plays an important role in biochemical processes. Some representative examples of this phenomenon include inhibition of human cytomegalovirus protease, ${ }^{16}$ inhibition of Ref- 1 , a therapeutic target for asthma, ${ }^{17}$ inactivation of cysteine proteases, ${ }^{18}$ blockade of platelet-derived growth factor BB-stimulated Akt phosphorylation, ${ }^{19}$ catalytic inhibition of human topoisomerase-2 alpha, an established target for the development of anticancer agents, ${ }^{20,21}$ etc. This encouraged us the study the reactivity of representative compounds in each of the series 1-5 and 9 towards a model thiol, benzyl mer- captan, under simulated physiological conditions These experiments were undertaken in order to evaluate whether the compounds in these series are in fact thiol alkylators and, if so, to determine the locus of thiolation. The results are summarized in Scheme 2. In the case of $\mathbf{1 d}, \mathbf{2 d}$, and $\mathbf{4 d}$, thiolation occurs at the olefinic carbon atom adjacent to the amidic group leading to $\mathbf{1 0}$ (from 1d) and $\mathbf{1 1}$ (from 2d and 4d). On the other hand, thiolation of the $E$-isomer $\mathbf{3 d}$ gave rise to $\mathbf{1 2}$ as the major product along with 10. The regiochemistry of thiol addition leading to compounds 10, 11, and 12 were confirmed by 1D NOESY experiments. One would expect thiolation to take place on the unsaturated carbon beta to amide carbonyl in case of $Z$ and $E$ acids (1d and 3d) and on the unsaturated carbon beta to ester carbonyl in case of $Z$ and $E$ esters (2d and 4d) on account of relatively higher electrophilicity of these carbonyl carbons. The anomalous thiol addition in case of 1d is presumably due to the increase in positive character of the carboxylate carbonyl which engages in intramolecular $\mathrm{H}$-bonding with the amide proton. Geometry of 3d does not permit the formation of an intramolecular H-bond. While the reaction of benzyl mercaptan with $\mathbf{5 d}$ led to the expected product 13, the isomaleimide $\mathbf{6 d}$ reacted with 2 M equiv of benzyl mercaptan to yield $\mathbf{1 4}$. This product presumably arose from an initial attack on the carbonyl carbon atom leading to ring opening and acylation of benzyl mercaptan followed by thiol addition at the olefinic bond. The conclusions drawn from these thiolation reactions are as follows. First, the compounds in series 1-6 alkylate thiols which is presumably one general way whereby cytotoxicity is mediated. Secondly, the differential reactivity leading to regioselective thiolation of $\mathrm{N}$-tolylmaleamic acid (1d) and $\mathrm{N}$-tolylfumaramic acid (3d) was found to be intriguing.

The confirmation of the thiol-alkylating properties of the compounds in series 1-6 suggests that interactions with important cellular constituents containing a mercapto group may be a significant contributor to the bioactivity observed. The enzyme hNMT catalyzes the transfer of a myristoyl group to the amino moiety of the terminal glycine residue of various proteins and the active site is believed to contain the mercapto group of the 169 -cysteine amino acid. ${ }^{22}$ In addition, a previous study revealed that the $\mathrm{IC}_{50}$ figures of $\mathbf{1 a , d , g , i}$ towards hNMT are 203, 53, 246, and $434 \mu \mathrm{M}$, respectively, while a concentration of $242 \mu \mathrm{M}$ of 1c stimulated the enzymatic activity by $50 \%{ }^{11}$

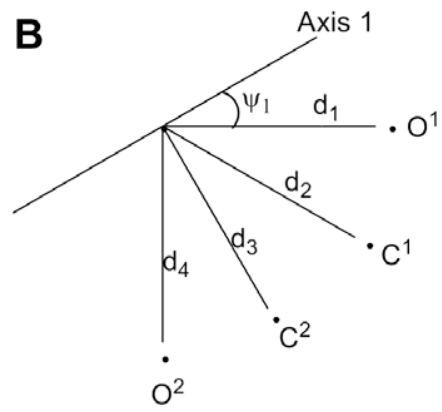

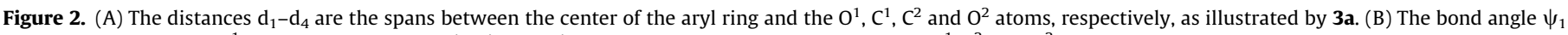

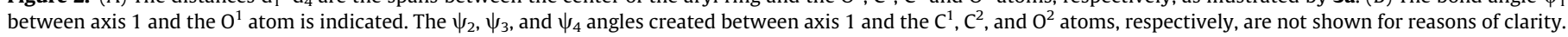


Table 3

Some interatomic distances and bond angles of $\mathbf{2 a} \mathbf{a} \mathbf{3} \mathbf{a}$, and $\mathbf{4 a}$

\begin{tabular}{|c|c|c|c|c|c|c|c|c|}
\hline \multirow[t]{2}{*}{ Compound } & \multicolumn{4}{|c|}{ Interatomic distances $(\AA)$} & \multicolumn{4}{|c|}{ Bond angles $\left({ }^{\circ}\right)$} \\
\hline & $\mathrm{d}_{1}$ & $d_{2}$ & $\mathrm{~d}_{3}$ & $\mathrm{~d}_{4}$ & $\psi_{1}$ & $\psi_{2}$ & $\psi_{3}$ & $\psi_{4}$ \\
\hline $\mathbf{2 a}$ & 3.88 & 5.24 & 5.98 & 5.06 & 25.61 & 50.17 & 61.56 & 85.37 \\
\hline $\mathbf{3 a}$ & 4.05 & 5.23 & 6.36 & 8.77 & 28.29 & 54.47 & 47.39 & 48.15 \\
\hline $4 a$ & 4.06 & 5.16 & 5.16 & 4.06 & 25.27 & 52.75 & 67.65 & 95.14 \\
\hline Average figure & 4.00 & 5.21 & 5.83 & 5.96 & 26.39 & 52.46 & 58.87 & 76.22 \\
\hline$\Delta \%^{\mathrm{a}}$ & 3.00 & 0.96 & 11.5 & 47.2 & 7.20 & 4.37 & 19.50 & 36.83 \\
\hline
\end{tabular}

a The $\Delta \%$ figures are the quotients of the maximum deviation from the average figure and the average figure expressed as a percentage.<smiles>Cc1ccc(NC(=O)/C=C\C(=O)O)cc1</smiles><smiles>Cc1ccc(NC(=O)C(CC(=O)O)SCc2ccccc2)cc1</smiles><smiles>COC(=O)/C=C/C(=O)Nc1ccc(C)cc1</smiles><smiles>Cc1ccc(NC(=O)C(CC(=O)O[Al])SCc2ccccc2)cc1</smiles><smiles>Cc1ccc(NC(=O)/C=C/C(=O)O)cc1</smiles><smiles>Cc1ccc(NC(=O)CC(SSc2ccccc2)C(=O)O)cc1</smiles><smiles>Cc1ccc(/N=C2\C=CC(=O)O2)cc1</smiles>

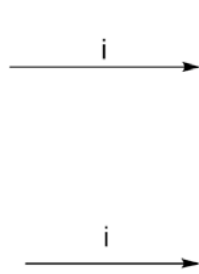<smiles>Cc1ccc(CO)cc1</smiles><smiles>CCNC(=O)C(CC(=O)SCc1ccccc1)SCc1ccccc1</smiles>

Scheme 2. Reaction of 1d, 2d, 3d, 4d, $\mathbf{5 d}$ and $\mathbf{6 d}$ with benzylmercaptan (BnSH). Reagents and conditions: (i) BnSH/MOPS buffer (pH 7.4): DMSO (1:1), $37{ }^{\circ} \mathrm{C}$.

In order to assess the ability of the compounds under investigation to inhibit hNMT, the $\mathrm{IC}_{50}$ values of the following compounds against hNMT were obtained, namely 2c: $431.6 \pm 6.92 \mu \mathrm{M}$; $2 d$ : $>10 \mathrm{mM}$; 3b: $1.60 \pm 0.35 \mathrm{mM}$; 3c: $4.38 \pm 1.59 \mathrm{mM}$; 3d: $8.35 \pm 0.21 \mathrm{mM}$; $\mathbf{3 e}$ : $7.55 \pm 2.2 \mathrm{mM}$; $3 \mathrm{~g}: 2.56 \pm 0.97 \mathrm{mM} ; \mathbf{4 b}: 400.0 \pm 1.5 \mu \mathrm{M} ; \mathbf{4 c}:>8.00$ $\mathrm{mM}$, and $4 \mathrm{e}: 2.33 \pm 0.81 \mathrm{mM}$.

The $\mathrm{IC}_{50}$ values of $\mathbf{2 c}$ and $\mathbf{4 b}$ are 432 and $400 \mu \mathrm{M}$, respectively. However the inhibition of the growth of Molt 4/C8, CEM and L1210 cells by these two compounds is achieved by substantially lower concentrations as the data in Table 1 indicates. Furthermore the $\mathrm{IC}_{50}$ values of $\mathbf{2 d}, \mathbf{3 c}, \mathbf{e}$, and $\mathbf{3 b} \mathbf{b}-\mathbf{e}, \mathbf{g}$ towards hNMT are all in excess of $500 \mu \mathrm{M}$. Hence inhibition of hNMT contributes only a very marginal effect in some cases towards the cytotoxicity displayed by the compounds prepared in this study whose principal modes of action are by other mechanisms.

Finally in considering one or more of the series 2-6 as lead molecules for further development, the tolerance of representative compounds in mice was undertaken. Doses of 30,100 , and $300 \mathrm{mg} / \mathrm{kg}$ of 2b-d,g,h, 3a-i, 4a-c,e-g,i, 5a-h, 6b,c,g,h, and 9 were administered to mice and the animals examined at the end of 0.5 and $4 \mathrm{~h}$. No mortalities were noted in the case of $\mathbf{2} \mathbf{b}, \mathbf{3} \mathbf{a}-\mathbf{i}, \mathbf{4} \mathbf{a}-\mathbf{c}, \mathbf{e}-\mathbf{g}, \mathbf{i}$ (i.e., all members of series $\mathbf{3}$ which were examined were tolerated by the mice) and 9. On the other hand, the remaining compounds viz $\mathbf{2 c , d , g , h , ~}$ all members of series $\mathbf{5}$ and $\mathbf{6}$ which were evaluated, namely $\mathbf{5 a - h}$ and $\mathbf{6 b}, \mathbf{c}, \mathbf{g}, \mathbf{h}$, led to deaths of the animals. The $\mathrm{N}$-arylfumaramic acids 3a-i, like the $N$-arylmaleamic acids $(\mathbf{1}),{ }^{11}$ did not cause any deaths in this bioassay. Detailed results on compounds showing mortality are as follows: Compound ID (dose in $\mathrm{mg} / \mathrm{kg}$, number of animals dead/ number of animals treated) after $0.5 \mathrm{~h}$, namely $\mathbf{2 d}(300,1 / 4)$ and $\mathbf{5 a}(300,2 / 4)$ while mortalities were noted at the end of the $4 \mathrm{~h}$ period after administration of $\mathbf{2 c}(300,2 / 2), \mathbf{4 d}(100,4 / 4 ; 300,1 / 2), \mathbf{2 g}$ (300, 2/2), $\mathbf{2 h}(300,2 / 2), \mathbf{5 a}(30,2 / 2 ; 100,4 / 4 ; 300,2 / 2), \mathbf{5 b}(100,4 /$ 4; 300, 2/2), 5c (300, 2/2), 5d (100, 4/4; 300, 2/2), 5e (100, 3/4), 5f $(100,4 / 4 ; 300,2 / 2), \mathbf{5 g}(100,2 / 4 ; 300,2 / 2), \mathbf{5 h}(100,4 / 4 ; 300,2 / 2)$, 6b $(300,1 / 2), \mathbf{6 c}(30,1 / 2 ; 100,3 / 4 ; 300,2 / 2), \mathbf{6 g}(100,1 / 4 ; 300,2 /$ $2)$, and $6 \mathbf{h}(300,1 / 2)$. These observations reveal a clear-cut advantage for pursuing the $N$-arylfumaramic acid esters $\mathbf{4}$ in contrast to the analogs in series $\mathbf{2 , 5}$, and $\mathbf{6}$.

In conclusion, this study has revealed that the enedione is a potential cytotoxic pharmacophore. In particular, the $\mathrm{N}$-arylfumaramic esters $\mathbf{4}$ are promising leads due to the cytotoxic potencies displayed and their tolerance by mice. Hence analog development of these novel cytotoxins 4 should be actively pursued in different ways. For example, the $\mathrm{N}$-arylfumaramoyl group could be attached by ester or amidic linkages to other cytotoxic molecules in order to produce a bifurcate toxicity to neoplasms. Quantitative and qualitative structure-activity relationships revealed various correlations between physicochemical properties and the $\mathrm{IC}_{50}$ figures generated. The reactions of representative compounds with a model thiol, namely benzyl mercaptan, confirmed that the enediones are thiol alkylators. 


\section{Acknowledgments}

The authors thank the following agencies for financial support, namely the Nova Scotia Health Research Foundation (A.J.), Canadian Institutes of Health Research (A.J., J.R.D., R.K.S), Fonds voor Wetenschappelijk Onderzoek-Vlaanderen (J.B., E.D.C.), and the Department of Biotechnology, DBT, New Delhi (A.K.P.). Appreciation is extended to Mrs. Lizette van Berckelaer for conducting the Molt 4/C8, CEM and L1210 assays, and the National Institute of Neurological Disorders and Stroke, MD, U.S.A. for undertaking the short-term toxicity studies in mice. Dr Mike Lumsden of Atlantic Region Magnetic Resonance Centre, Dalhousie University is thanked for his help in recording 1D NOESY experiments on certain samples.

\section{Supplementary data}

Supplementary data associated with this article can be found, in the online version, at doi:10.1016/j.bmcl.2010.01.098.

\section{References and notes}

1. Jha, A.; Duffield, K. M. Indian J. Chem., Sect. B 2006, 45, 2313.

2. Pati, H. N.; Das, U.; Sharma, R. K.; Dimmock, J. R. Mini-Rev. Med. Chem. 2007, 7 131.

3. Jha, A.; Mukherjee, C.; Prasad, A. K.; Parmar, V. S.; De Clercq, E.; Balzarini, J.; Stables, J. P.; Manavathu, E. K.; Shrivastav, A.; Sharma, R. K.; Nienaber, K. H.; Zello, G. A.; Dimmock, J. R. Bioorg. Med. Chem. 2007, 15, 5854
4. Jha, A.; Mukherjee, C.; Rolle, A. J.; De Clercq, E.; Balzarini, J.; Stables, J. P. Bioorg. Med. Chem. Lett. 2007, 17, 4545.

5. Jha, A.; Zhao, J.; Cameron, T. S.; De Clercq, E.; Balzarini, J.; Manavathu, E. K.; Stables, J. P. Lett. Drug Des. Discovery 2006, 3, 304.

6. Dimmock, J. R. Jha, A. Zello, G. A. Quail, J. W: Oloo, E. O. Nienaber, K. H. Kowalczyk, E. S.; Allen, T. M.; Santos, C. L.; De Clercq, E.; Balzarini, J.; Manavathu, E. K.; Stables, J. P. Eur. J. Med. Chem. 2002, 37, 961.

7. Jha, A.; Dimmock, J. R. Synth. Commun. 2003, 33, 1211.

8. Mutus, B.; Wagner, J. D.; Talpas, C. J.; Dimmock, J. R.; Phillips, O. A.; Reid, R. S. Anal. Biochem. 1989, 177, 237.

9. Baluja, G.; Municio, A. M.; Vega, S. Chem. Ind. 1964, 2053.

10. Okey, A. B.; Harper, P. A. In Principles of Medical Pharmacology; Kalant, H., Grant D. M., Mitchell, J., Eds., 7th ed.; Elsevier: Toronto, Canada, 2007; p 902.

11. Dimmock, J. R.; Jha, A.; Zello, G. A.; Sharma, R. K.; Shrivastav, A.; Selvakumar, P.; Allen, T. M.; Santos, C. L.; Balzarini, J.; De Clercq, E.; Manavathu, E. K.; Stables, J. P. J. Enzyme. Inhib. Med. Chem. 2003, 18, 325.

12. Lowe, D. Chem. World 2008, 5, 18.

13. Sauers, C. K. J. Org. Chem. 1969, 34, 2275.

14. Haval, K. P.; Mhaske, S. B.; Argade, N. P. Tetrahedron 2006, 62, 937.

15. Suffness, M.; Douros, J. In Methods in Cancer Research, Part A; De Vita, V. T., Jr., Busch, H., Eds.; Academic Press: New York, 1979; Vol. 16, p 84.

16. Peseckis, S. M.; Resh, M. D. J. Biol. Chem. 1994, 269, 30888.

17. Pinto, I. L.; Jarvest, R. L.; Clarke, B.; Dabrowski, C. E.; Fenwick, A.; Gorczyca, M. M.; Jennings, L. J.; Lavery, P.; Sternberg, E. J.; Tew, A. Bioorg. Med. Chem. Lett. 1999, 9, 449.

18. Nguyen, C.; Teo, J.-L.; Matsuda, A.; Eguchi, M.; Chi, E. Y.; Henderson, W. R., Jr.; Kahn, M. Proc. Natl. Acad. Sci. 2003, 100, 1169.

19. Darkins, P.; Gilmore, B. F.; Hawthorne, S. J.; Healy, A.; Moncrieff, H.; McCarthy, N.; McKervey, M. A.; Brömme, D.; Pagano, M.; Walker, B. Chem. Biol. Drug Des. 2007, 69, 170.

20. Youssef, D.; Potter, E.; Jha, M.; De Clercq, E.; Balzarini, J.; Stables, J. P.; Jha, A. Bioorg. Med. Chem. Lett. 2009, 19, 6364.

21. Yellaturu, C. R.; Bhanoor, M.; Neeli, I.; Rao, G. N. J. Biol Chem. 2002, 277, 40148

22. Jensen, L. H.; Renodon-Corniere, A.; Wessel, I.; Langer, S. W.; Søkilde, B.; Carstensen, E. V.; Sehested, M.; Jensen, P. B. Mol. Pharmacol. 2002, 61, 1235. 